\title{
Numerical Methodology in Comparative Tax Law: the Mathematical Model of Elasticity as a Thinking Model for Legal Comparisons
}

\author{
Ruben Martini
}

\begin{abstract}
Although the field of comparative tax law has achieved greater prominence in legal studies, its methodology is not yet adequately developed. In general, work in comparative tax has not focused adequately on specific features of tax law. This paper proposes a comparative methodology specifically designed to make use of this unique relationship between tax law and private law. Based on a historical overview of comparative tax law and its methodology, it proposes the adoption of the numerical concept of elasticity, regularly used in mathematics and economics, for tax comparisons. This numerical tool, which measures how changing one variable affects others, seems to be particularly suitable to analyse the interaction of tax provisions with underlying private law concepts in a systematised manner. Used as a thought pattern and a foundation for future work, such a numerical analysis is able to identify interrelations between tax law and its private law environment that are likely to be overlooked by classical text-based comparisons. This can aid legislative reform, as it reduces its 'trial- and-error' aspect. At the same time, the numerical approach disassociates comparative analyses from the impreciseness of text-based data.
\end{abstract}

* University of Heidelberg, Institute for Finance and Tax Law, Research Associate.

Copyright (c) the Author(s).

This work is licensed under a Creative Commons Attribution-NonCommercial-NoDerivs 3.0 License. 


\section{Introduction}

Although the field of comparative tax law has achieved greater prominence in legal studies, its methodology is not yet adequately developed. This deficiency can be remedied by focusing on the specific relationship of tax law and private law as well as on legislators as addressees of comparative results.

In the majority of cases, the methods of general comparative law are transferred to tax comparisons without appropriate reflection. ${ }^{1}$ Such parallelism of methods, however, is in danger of overlooking one of the main specificities of tax law: its unique connection to private law. Compared to other areas of law, tax provisions are not structured as much around factual scenarios. Rather, they rely on the legal prestructuring of reality that private law provides. Tax provisions usually refer to private law terms and concepts, such as the concepts of corporations and partnerships in income tax, the conclusion of a contract in property transfer tax, and ownership in property tax.

At the same time, the lack of a specific methodology often results in tax comparisons being influenced by national perspectives. Often, comparisons are conducted to provide insights into the researcher's own jurisdiction. The differences with foreign law are used to identify the specificities of the researcher's own national laws. The subsequent analysis of this legislation, however, is typically based on purely domestic non-legal factors, such as national political or economic circumstances. In this regard, the comparative perspective does not add anything essential to the analysis.

However, a specific function can be assigned to comparative tax law by stressing its addressees: national legislators. Legislators require knowledge about their tax system that is not just descriptive, but that explains the possibilities for legal reform. Therefore, they need to know how tax law relates to other fields of law. Comparative tax law at its current stage, however, merely describes the differences between foreign legal concepts and ideas. It does not interrelate these concepts with their respective legal environment.

This is where the connection between tax law and private law comes in. By analysing the relationship between a superordinate tax law concept and a given private law concept across several jurisdictions, unique comparative knowledge can be obtained that is not connected to a particular jurisdiction. Such an analysis identifies interrelations between tax law and its legal environment that

1 Cf V Thuronyi, 'Tax law', in J M Smits (ed), Elgar Encyclopedia of Comparative Law (2008) 709. A typical example of a comparison based on a general methodology is H Ault \& B Arnold (eds), Comparative Income Taxation (2010). 
are likely to be overlooked by comparisons that adopt a domestic perspective. In this way, comparative analysis produces systematised results that separate a tax law concept from the characteristics of the national legal system in which it was developed; the concept becomes convertible. Such comparative knowledge allows legislators to introduce new concepts into their tax system, or adapt existing provisions, while avoiding conflicts with the national private law. To a certain extent, such preparatory works reduce the aspect of 'trial-and-error' in legislative reforms. $^{2}$

In order to make use of the relationship between tax law and private law for purposes of comparative law, this paper proposes to adopt the concept of elasticity, regularly used in mathematics and economics, for analysis in comparative tax law. In economics, elasticity is the measurement of how changing one economic variable affects others. ${ }^{3}$ An elastic variable is one which responds more than proportionately to changes in other variables, while an inelastic variable is one which changes less than proportionately in response to changes in other variables. This method can provide a numerical systematisation of the effects of changes of one concept to other concepts. By using this mathematical model as a thought pattern and a foundation for future work, the interaction of tax provisions with underlying private law concepts can be examined in a systematised manner. In short, the elasticity approach measures the influence of private law on the shape and effectiveness of tax law provisions.

Based on these assumptions, the methodological background of comparative tax law will be addressed in two steps. The paper first examines the historical evolution of comparisons in the field of tax law. This historical development is not characterised by a replacement of methods, but by a consistent development of comparative techniques. For the most part, the different stages constitute a consistent system whose steps are the archetype of every comparison.

Initially, comparative tax law had a mere descriptive character. It was little more than a recording of the different provisions in national jurisdictions (below at $\$ 2$ ). In the second stage, the wording of different provisions was compared from a functional point of view (below at $\$ 3$ ). The third stage, which is the current stage of comparative tax law, focuses on models that are able to explain and evaluate the similarities and differences identified by text-based comparison (below at \$4). This third stage, unlike the first two, is characterised by a diversity

\footnotetext{
2 Below, $\$$ 5.3.4.

3 The most prominent example is the price elasticity of demand which, in simple terms, gives an answer to the following questions: 'If I lower the price of my product, how much more will I sell?' and 'If I raise the price, how much less will I sell?'.
} 
of methods. These methods, however, are also used in comparative law in general. Approaches that focus on the specificities of tax law are exceptional.

This is why this article, in its second part, will seek to develop a methodology specific to comparative tax law (below at $\$ 5$ ). It proposes to adopt the notion of elasticity, as this concept allows us to examine the specific interrelation between tax law and private law and to consider the special characteristics of tax law. At the same time, the interpretation and systematisation of comparative results by a numerical approach disassociates them from the impreciseness of text-based data. ${ }^{4}$

\section{Description of foreign law}

The first systematic approaches to comparative tax law were developed during the interwar period, largely through the work of the German tax administration and academia in financial science which was institutionalised in the Treaty of Versailles. ${ }^{5}$ To ensure the payment of reparations, the treaty provided that the overall German tax burden should be equal to the highest tax burden in the victorious powers. ${ }^{6}$ In order to determine the minimum tax burden in the Weimar Republic, a comparison with the tax burdens in other states was necessary. The German tax administration was obliged to conduct regular international comparisons of tax burdens, for which it partly relied on academic research in financial science.

4 Below, $\$ 5.1$.

5 An earlier example is O Schwarz, Die Steuersysteme des Auslands (1908).

6 Treaty of Versailles, 28 June 1919, 225 CTS 188, Annex 2, Art 12(b): 'In periodically estimating Germany's capacity to pay, the Commission shall examine the German system of taxation, first, to the end that the sums for reparation which Germany is required to pay shall become a charge upon all her revenues prior to that for the service or discharge of any domestic loan, and secondly, so as to satisfy itself that, in general, the German scheme of taxation is fully as heavy proportionately as that of any of the Powers represented on the Commission.' Under Annex 2, Art 2(1) delegates to the commission would be nominated by the United States of America, Great Britain, France, Italy, Japan, Belgium and the Serb-Croat-Slovene State.

7 See Statistics Agency of the German Reich, Internationaler Steuerbelastungsvergleich (1933) $6 \mathrm{ff}$. On the state-of-the-art public economics that at that time formed the basis for the Statistics Agency, see E Seligman, 'Comparative tax burdens in the twentieth century' (1924) 39 Political Science Quarterly 106; K Bräuer, 'Ertragsteuern', in W Gerloff \& F Neumark (eds), Handbuch der Finanzwissenschaft, vol 2 (1927) 6ff; I Hosiosky, Die methodischen Grundlagen internationaler Steuerbelastungsvergleiche (1929); E Lindahl, Aktiebolagens Beskattning i Sverige och Utlandet (1931); A Angelopoulos, Charges fiscales et dépenses publiques (1932). 
These analyses inevitably required a knowledge-at least a basic one-of foreign tax systems. The textual description of foreign laws was therefore a regulatory task of the tax administration. Tax academics, however, used text-based national reports merely as preparatory works for the comparisons of tax burdens that were nearly exclusively focused on the tax rate. The text-based results were not considered as having any independent value. ${ }^{8}$ In fact, the different tax systems were compared on a mere quantitative basis. Qualitative aspects that are essential for comparative legal science were disregarded. ${ }^{9}$

To a certain extent, the League of Nations went beyond a mere collection of data. It focused on the avoidance of international double taxation and the development of a model tax convention. ${ }^{10}$ Not only were national provisions with an international scope examined, but also the tax systems as a whole, using an encyclopaedic approach. ${ }^{11}$ Later, the description of national tax law was disassociated from its initial purpose as a preparatory work. In light of the global economic crisis at that time, the League of Nations focused on tax legislators as the addressees of the results of comparative analyses. In the view of the League of Nations, tax provisions that had been adapted to the changes in the global economic environment should have served as a model for reforms in other jurisdictions. ${ }^{12}$ Unfortunately, the development of a corresponding comparative

${ }^{8}$ Lindahl, above $\mathrm{n} 7,33$, had already suggested skipping the text-based analysis and advancing to the charts on tax burdens.

${ }^{9}$ Purely quantitative approaches are closely related to public finance. However, if quantitative data is then again used as the basis for a qualitative comparison, this would be comparative law based on a realistic approach. Comparative aspects, however, did not play a significant role in legal realism at that time. H Kantorowicz, 'Some rationalism about realism' (1933) 43 Yale LJ 1240, 1244, did not seem to have considered the differences between the common law and the private law tradition.

${ }^{10} \mathrm{Cf}$ the initiatives of the Economic and Financial Committee that lead to the following League of Nations reports: B Blackett, Memorandum on Double Taxation (1921); B Blackett, Note on the Effect of Double Taxation upon the Placing of Investment Abroad (1921); G Bruins et al, Report on Double Taxation (1923); M Carroll, The Taxation of Foreign and National Enterprises-Methods of Allocating Taxable Income, vol 4 (1933) 169ff; R Jones, Taxation of Foreign and National Enterprises-Allocation Accounting for the Taxable Income of Industrial Enterprises, vol 5 (1933). An overview of the activities of the League of Nations in the field of public finance is given by J Berolzheimer, 'Probleme internationaler Finanzvergleiche', in W Gerloff \& F Neumark, Handbuch der Finanzwissenschaft, vol 4 (1965) 81ff.

${ }^{11}$ Taxation of Foreign and National Enterprises, vols 1-3 (1933), which was published in the Series of League of Nations Publications. This publication covers, besides the most important European tax systems, Canada, Mexico, Japan, South Africa and the US. Cf from the same period R Rosendorff \& J Henggeler, Das internationale Steuerrecht des Erdballs (1936).

${ }^{12}$ League of Nations, Report to the Council on the Fourth Session of the Committee, 26 June 1933, 4. 
method was frustrated by the outbreak of the Second World War.

\section{Text-based comparison and functionalism}

In the post war period, tax scholars began to comprehensively define international similarities and national specificities based on descriptive data concerning foreign tax law. ${ }^{13}$ This development, much like contemporary comparative tax law, was considerably influenced by the International Fiscal Association (IFA). Through its congresses, the IFA produces general reports, which are of crucial importance to comparative analyses since they build on nationals reports that provide systematic descriptions of foreign tax laws. In most cases, however, the general reports limit themselves to descriptions of similarities and differences between tax regimes. ${ }^{14}$ Such a method bears the risk of being exclusively focused on the technicalities. The knowledge that it produces is of limited use to practical application and legal reforms. ${ }^{15}$

Besides text-based comparisons, the IFA applies the functional method that has a predominant position in comparing private law. ${ }^{16}$ From the beginning, IFA congresses have focused on practical questions. This focus confines the national reports to providing specific legislative reactions to the questions posed by the congresses, preceding the actual comparison. ${ }^{17}$ In this way, functionalism

${ }^{13}$ An early example of a text-based comparison is A Hoffmann, Die Besteuerung des Gewinnes der kaufmännischen Unternehmung im Ausland (1934) 287ff. P di Malta, Droit fiscal européen comparé (1995), however, still remains on the descriptive level.

${ }^{14}$ See e.g. R Patrick, 'General report' (1980) 65b Cahiers de Droit Fiscal International 15 on rules for determining income and expenses as domestic or foreign.

${ }^{15}$ For a text-based comparison see E Eberle, 'The method and role of comparative law', <http://ssrn.com/abstract=1265659> [accessed 30 October 2012] 22ff. The epistemic value of a solely text-based comparison is tackled in J Mössner, 'Why and how to compare tax law', in C Sacchetto et al (eds), Introduction to Comparative Tax Law (2008) 13, 15. General aspects are addressed by A Tschentscher, 'Dialektische Rechtsvergleichung-Zur Methode der Komparistik im öffentlichen Recht' (2007) Juristenzeitung 809.

${ }^{16}$ E Reimer, 'Der Rechtsvergleich im Internationalen Steuerrecht-Fragestellungen und Methoden', in M Lehner (ed), Reden zum Andenken an Klaus Vogel (2010) 93. For the functionalism applied in private law see E Rabel, 'Aufgabe und Notwendigkeit der Rechtsvergleichung' (1924) Rheinische Zeitschrift für Zivil- und Prozeßrecht 279; K Zweigert \& H Kötz, Einführung in die Rechtsvergleichung (1996) 33. Transferring functionalism to comparative tax law is promoted by C Garbarino,'Le basi teoriche ed i metodi del diritto tributario comparato' (2004) Diritto Pubblico Comparato ed Europeo 1059, 1070; C Garbarino, 'An evolutionary approach to comparative taxation: methods and agenda for research' (2009) 57 AJCL 677, 686.

${ }^{17}$ A typical example is the second topic of the 1959 congress in Madrid, which addressed different 
merely helps to select the objects of analysis. It does not provide any guidelines concerning the methodology of the comparison itself. ${ }^{18}$

In contrast to comparative projects and concepts in private law, whose purpose is defined by identifying a 'common core ${ }^{19}$ or a 'common frame of reference, ${ }^{20}$ comparative tax law currently lacks a purposive orientation. The topics of the IFA congresses and their reports lack a comprehensive aim. They fail to go beyond a purely functional selection of the object of comparison, which, in the end, could methodologically influence the comparative techniques. The potential aims of a comparative analysis of tax law suggested by the League of Nations are not pursued. ${ }^{21}$

\section{$4 \quad$ Plurality of methods}

As in the 'postmodern' stage of comparative law in general, tax scholars increasingly deviate from an exclusive focus on functional equivalents, which are perceived as suffocating and mono-dimensional. ${ }^{22}$ Contemporary approaches to

national reactions to a factual problem: 'Les mesures fiscales destinées à faciliter le mouvement international des capitaux' (1959) 39 Cahiers de Droit Fiscal International 293.

${ }^{18}$ R Martini, 'Über die Rezeption von Steuergesetzen' (2011) Steuer und Wirtschaft 18, 22ff. The understanding of comparative law as the analysis of legal formants is promoted by R Sacco, 'Legal formants: a dynamic approach to comparative law' (1991) 39 American Journal of Comparative Law 1, 21. This analysis includes, besides the textual sources, cultural, individual and similar influences. See also M Bussani \& U Mattei, 'The common core approach to European private law' (1997) 12 Columbia JEL 339, 344ff; P Monateri, 'Legal formants and competitive models: understanding comparative law from legal process to critique in cross-system legal analysis', $<$ http://ssrn.com/abstract=1317302> [accessed 30 October 2012].

19 See R Schlesinger, 'Research on the general principles of law recognised by civilized nations' (1957) 51 AJIL 734, 739ff and R Schlesinger, Formation of contracts, vols 1-2 (1968). This approach was resumed by the so-called 'Trento-Project'; see M Bussani \& U Mattei, above n 18, 343ff; M Bussani \& U Mattei, 'Preface', in M Bussani et al (eds), The Common Core of European Private Law (2002) 1ff.

${ }^{20}$ See O Lando, Principles of European Contract Law, vols 1-2 (2000); O Lando, Principles of European Contract law, vol 3 (2003); C von Bar, 'A common frame of reference for European private law-academic efforts and political realities' <http://www.ejcl.org/121/art121-27.pdf> [accessed 31 October 2012].

${ }^{21}$ See above at $\$ 2$ and the sources cited above at $\mathrm{n} 10$.

${ }^{22}$ The application of the functional approach in comparative tax is viewed critically by A Infanti, 'Spontaneous tax coordination: on adopting a comparative approach to reforming the US international tax regime' (2002) 35 Vanderbilt JTL 1105, 1140ff; W Barker, 'Expanding the study of comparative tax law to promote democratic policy: the example of the move to capital gains taxation in post-apartheid South Africa' (2005) 109 Penn State LR 101, 104ff. See for this criticism 
comparative tax law depart from textual analysis and adopt a plurality of methods. These approaches concentrate on the factors that influence the actual shape of tax provisions. In many cases, today's comparative tax law analyses blur the borders between juridical science and its neighbouring disciplines. The findings of technical text-based comparisons form the starting point for political science as well as for sociological and economic research. ${ }^{23}$ These methods are also used in comparative law in general. On the one hand, this avoids having to rely on functionalist techniques. On the other, these general instruments of comparison do not always take into account the specificities of tax law, which creates a number of risks.

First, applying a plurality of methods harbours the risk of diffused results. As is the case with other fields of law, the similarities and differences between legal systems can be explained by a range of social, political and economic circumstances. While tax law is closely connected to economic circumstances, this connection is not an exclusive one. Company law, the law of economic offences, social security regulations and many other fields offer a comparable environment.

Second, contemporary approaches to comparative tax law use textual comparisons to identify those parts of the studied object to which the different nonlegal methods have to be applied. ${ }^{24}$ Their application, however, is not a comparison as such. Sociological, political or economic techniques are monodimensionally applied to different national rules. They are primarily used to explain the concrete shape of a national provision. This can also be done from a purely domestic perspective. The connection of a tax provision to certain sociological, political or economic circumstances analyses only one jurisdiction at a time and

in general P Legrand, 'Comparative legal studies and commitment to theory' (1995) 58 Modern Law Review 262, 266; P Legrand, 'European legal systems are not converging' (1996) 45 ICLQ 52, 59ff; A Peters \& H Schwenke, 'Comparative law beyond post-modernism' (2000) 49 ICLQ 800, $811 \mathrm{ff}$.

${ }^{23}$ A historical-political approach is applied by A Mehrotra, 'The public control of corporate power: revisiting the 1909 US corporate tax from a comparative perspective' (2010) 11 Theoretical Inquiries in Law 497, 521ff. K James, 'An examination of convergence and resistance in global tax reform trends' (2010) 11 Theoretical Inquiries in Law 475, 489ff compares tax law considering the role of veto powers. Sociological methods are used by M Livingston, 'From Milan to Mumbai, stopping in Tel Aviv: progressive taxation and politics in a globalized but still local world' (2005) 18 Can JILJ 119. See for a comparison on an economic basis C Sandford, Why Tax Systems Differ: A Comparative Study of the Political Economy of Taxation (2000).

${ }^{24}$ Similarly in the field of comparative law in general: N Jansen, 'Comparative law and comparative knowledge', in M Reimann et al (eds), The Oxford Handbook of Comparative Law (2006) 336. 
therefore-in the majority of cases-relies on univariate data. ${ }^{25}$ Such data, however, does not lead to true comparative or universal knowledge that goes beyond one particular jurisdiction.

\section{Elasticity as a multivariate method}

These methodological deficits can be reduced by adopting a multivariate method of analysis, focusing on the interrelation of tax law, private law and, especially, company law. This means that the object of comparison not only encompasses the specific tax provision, but also its (private law) environment. The problem is how to methodologically deal with such multivariate data. A possible solution is to make use of mathematical and economic elasticity to analyse the relationship between two variables. By using this method as a cognitive model for legal analyses, we can place a numerical level between the text-based comparison and the legal interpretation of the results. Such a threefold comparison fulfils two purposes: on the one hand, two sets of data can be logically interrelated; on the other hand, the connection between tax law and private law can be included in the comparison.

\subsection{Multivariate analyses as a challenge for legal comparisons}

As we have seen, neither functionalist nor 'postmodern' approaches to comparative tax law necessarily rely on comparative methodologies. As a result, their findings remain confined to the particular jurisdiction under investigation. Legal comparison, however, can be used to obtain genuine comparative knowledge. Such 'universal' information is not related to a certain legal environment, national conditions or domestic institutions. It can be applied in every jurisdiction.

One possible way to acquire such knowledge is multiplying the perspective of comparison. The comparative basis can be broadened by interrelating modifications and similarities of national tax provisions on the one hand, and the wider legal environment on the other. ${ }^{26}$ In contrast to 'postmodern' approaches, this multivariate model does not aim to explain differences and similarities

\footnotetext{
25 This is true for comparisons that do not include a longitudinal perspective. Studies over time include bivariate and multivariate data. They are, however, still connected to one jurisdiction which is analysed over time. Thus, the results of such historical comparisons cannot be transferred to other jurisdictions without further ado.

${ }^{26}$ Cf also V Thuronyi, Comparative Tax Law (2003) 7; similarly Mössner, above n 15, 26.
} 
through a range of non-legal methods. Rather, it entails the systematisation of the multidimensional interaction of certain parts of a legal provision with other areas of law. This system permits the creation of a universally applicable model that is completely disassociated from national law; it can adapt to different situations based on knowledge acquired by a genuine comparison of law.

However, such multivariate data is difficult to derive from qualitative, text-based analysis. Qualitative research often fails to differentiate between, on the one hand, the relations between different national tax regimes, and on the other, the links with their respective legal environments. Without a clear systematisation, the numerous levels of analysis easily become confused. In addition, the systematisation of the results is jeopardised by different legal vernacular among legal systems; each legal system employs its own words, which may be different from each other even when concepts they refer to are the same. A mechanism is thus needed that is able to consistently and coherently systematise the different relations existing among the results of the text-based comparison.

In order to avoid the imprecision of text-based analyses, it would make sense to partly disassociate the comparison from the purely qualitative level and to enrich it with quantitative characteristics. An example of such a method is the research of Ekkehart Reimer. Reimer deals with the implementation of taxation on a net basis in the field of income from employment. ${ }^{27}$ In order to make the different national concepts comparable, he uses quantitative indicators (1 to 3 ) to display the different grades of deductibility of the expenses included in the analysis. $^{28}$

The most important aspect of such a method is the transfer of text-based results into numerical indicators. The sensibility of this transfer is highlighted by the fact that the determination of the indicators is dependent on a qualitative evaluation. $^{29}$ It is crucial, however, that the translation of qualitative results to quantitative data is based on consistent criteria. These criteria have to lead to reproducible results that constitute a valid basis for the comparability of the data.

Such a transfer is possible with deductible expenses. The need for a more or less freehand transfer as used in the analysis of Reimer is not essential. The chosen part of the income from employment is widely characterised by a numerical basis. In theory, the indicators that function as a link between language and numbers could, without major difficulties, be made obsolete by using empirical data. For

\footnotetext{
${ }^{27}$ E Reimer, 'Das objektive Nettoprinzip aus gemeinschaftsrechtlicher, abkommensrechtlicher und rechtsvergleichender Sicht' (2009) 34 Deutsches Steuerrecht (attachment) *122, *126ff.

${ }^{28}$ See especially the results in ibid, ${ }^{*} 128$.

${ }^{29} \mathrm{Ibid},{ }^{*} 126$.
} 
example, the grade of deductibility could be reflected in absolute numbers or in relation to the tax base, to the tax debt or the average purchasing power. ${ }^{30}$

Reimer's method, however, is necessarily based on legal provisions whose effects can be expressed in numbers. In the special case of deductibility of expenses, the use of indicators may lead to valid results. The univariate indicators, however, ignore the non-numerical parts of the provision under analysis, as well as its legal environment. ${ }^{31}$ Without major adaptations, such a methodology cannot be applied to provisions with exclusively qualitative effects; nor is it possible to include the interaction of the compared object with other fields of law. Hence, a transfer of this approach to comparative tax law in general does not seem to be appropriate. As regards other areas of law, the use of quantitative indicators is of even less use.

A solution to this dilemma can be found in mathematics. The mathematicaleconomic concept of elasticity measures how changes of a certain parameter affect another variable. Used as a thinking model, this ratio fits with the idea of comparative tax law as an analysis of the interrelation of different tax provision and their legal environments. In contrast to the indicators Reimer uses, such a method can also be applied to provisions whose effects cannot be fully expressed in numbers.

Similar to the problems faced by the indicators, the use of the concept of elasticity requires a consistent and coherent algorithm to translate the results of text-based comparisons into a numerical system. A quantitative model based on these premises offers the opportunity to logically systematise the interrelation of a tax concept with other (not necessarily tax-related) concepts. As a final outcome, this model can be an instrument to empirically determine if and to what extent there is a connection or conflict between the tax provision under comparison and the legal environment included in the analysis.

In order to transfer this model-originally exclusively based on numerical data-to comparative tax law, the mathematical concept of elasticity has to be examined (below at \$5.2). Secondly, the numerator and the denominator, i.e. the dependent variable and the given parameter, have to be defined for the use of comparative tax law (below at \$5.3.1-2). As regards the specific elasticities, the impreciseness of the data of the text-based comparison results in a twofold

\footnotetext{
${ }^{30}$ This approach is followed by a project sponsored by the German Research Foundation: 'Taxation of employment income on gross or net basis? The development of a quantitative methodology of comparative tax law'. See <http://gepris.dfg.de/> [accessed 30 October 2012].

${ }^{31}$ Reimer, above $\mathrm{n} 27,{ }^{*} 126 \mathrm{ff}$ indicates that the interaction of the different tax deductions with social law is not included in the analysis.
} 
binary approach. The concept under analysis is either identical in the compared jurisdictions or it is subject to change. Therefore, changes of the concept can only be measured on a nominal scale, i.e. by '+' and '-', but not regarding their extent (below at \$5.3.3).

\subsection{Mathematical elasticity}

In a nutshell, the mathematical concept of elasticity describes the changes of variables that are functionally connected. In particular, it is used by economists in order to describe and systematise the reactivity of economic variables. ${ }^{32}$ The basic definition of elasticity $(\varepsilon)$, the arc elasticity, compares the impact of the given changes of the parameter on the variable under analysis. It is defined by the ratio of the relative change of a dependent variable $\frac{\Delta y}{y}$ with respect to the relative change of a given parameter $\left(\frac{\Delta x}{x}\right)$.

$$
\varepsilon_{x, y}=\frac{\frac{\Delta y}{y}}{\frac{\Delta x}{x}}
$$

In order to disassociate this relationship from a concrete change of the parameter, the differences are substituted by differentials. The relationship between $y$ and $x$ is expressed by the formula $y=f(x)$. A change of $x(\Delta x)$ results in a change of $y$ which is represented by $\Delta y=f(x+\Delta x)-f(x)$. Thus, a relative change of $x$ by $\Delta x$ results in a relative change of $y$ by

$$
\frac{\Delta y}{y}=\frac{f(x+\Delta x)-f(x)}{f(x)}
$$

In order to adapt this relationship to infinitesimal changes of the parameter (point elasticity), the equation (1) has to be considered under the condition of $\Delta x \rightarrow 0$. Inserting the equation (1) in (2) leads to:

$$
\lim _{\Delta x \rightarrow 0}=\frac{\frac{f(x+\Delta x)-f(x)}{f(x)}}{\frac{\Delta x}{x}}=\lim _{\Delta x \rightarrow 0} \frac{f(x+\Delta x)-f(x)}{\Delta x} \cdot \frac{x}{f(x)} .
$$

\footnotetext{
32 The most prominent example is the price elasticity of demand $(x=x(p))$ with $x$ defining the quantity demanded of a good or service and $p$ defining its price. See J Tietze, Einführung in die angewandte Wirtschaftsmathematik (2011) 308. Cf T Pampel, Mathematik für Wirtschaftswissenschaftler (2010) 120ff; for elasticities considering taxes see S Giertz, 'The Elasticity of Taxable Income during the 1990s: New Estimates and Sensitivity Analyses' (2010) 77 Southern Economic Journal 406; J Creedy \& J Sanz-Sanz, 'Revenue Elasticities in Complex Income Tax Structures: An Application to Spain', (2010) Fiscal Studies 535.
} 
Under the condition that

$$
f^{\prime}(x)=\lim _{\Delta x \rightarrow 0} \frac{f(x+\Delta x)-f(x)}{\Delta x}
$$

applies, the equation of elasticity for all $y$ with respect to $x$ is

$$
\varepsilon_{x, y}=\frac{f^{\prime}(x) \cdot x}{f(x)}=y^{\prime} \cdot \frac{x}{y} .
$$

For both types of elasticity, the responsiveness of the dependent variable to changes of the parameter can be classified in five different stages. In the case of $\varepsilon=0$, there is a perfectly inelastic reaction. The dependent variable is fixed and does not at all react to changes of the parameter. This results in $\Delta y=0$. In this case, the function $y=f(x)$ is constant. Such a function does not have a slope. This means that the derivative is $y^{\prime}=0 .{ }^{33}$

If the absolute values of $\varepsilon$ lie between 0 and $1(0<|\varepsilon|<1)$, the reaction of the dependent variable $(y)$ is relatively inelastic. There is a change, but its relative value is less than the relative change of the parameter. ${ }^{34}$ In the case of $|\varepsilon|=1$, the responsiveness is unitarily elastic. The relative change of the dependent variable is equal to the relative change of the parameter. ${ }^{35}$ If the relative change of $y$ is greater than the relative change of the parameter $(|\varepsilon|>1)$, there is a relatively elastic responsiveness. ${ }^{36}$ In extreme cases, a perfectly elastic responsiveness can occur. This means that changes of the parameter-irrespective its value-result in an infinite change of the dependent variable $(|\varepsilon| \rightarrow \infty) .{ }^{37}$

\subsection{Transfer to comparative tax law as a thinking model}

Since it is a mathematical operation, the concept of elasticity cannot be used as a comparative method without modifications. Such a transfer is not a question

\footnotetext{
${ }^{33}$ Concerning the price elasticity of demand, this means that demand is completely independent from price. Such situations occur in the case of goods that are not substitutable.

${ }^{34}$ In this situation, there is only a minor reaction of the consumers on alterations in prices. Such a reaction is caused by price changes of goods that are marginally substitutable (e.g. meat).

35 The demand is linear. A change in prices of one percent results in a change of demand of one percent.

${ }^{36}$ Such reactions occur in the case of substitutable goods (e.g. luxury articles).

${ }^{37}$ Even a marginal change in prices results in an infinite change of demand. In practice, such a situation may occur if a constant price coincides with perfect substitutability.
} 
of merely applying economic methods to comparative law. ${ }^{38}$ Rather, the idea of elasticity, as derived from mathematics and economics, shall be used as a thinking model for a systematisation of tax law comparisons that are still exclusively based on legal methods.

The process of translating law into numbers is merely transitional. It does not represent a self-contained analysis. The idea of elasticity is only to be used as a numerical model to inspire a jurisprudential and therefore qualitative approach to description and systematisation of results of comparative legal study. ${ }^{39}$ Such a usage of mathematics does not mean a quantitative analysis of law. Unlike empirical legal studies, the elasticity method does not directly deal with the relationship between law and reality. Rather, it is used as a translational model. In contrast to quantitative methods, the numerical approach is based on data that is not derived from empirical research, but from the transfer of language into numbers.

This approach, however, has to take account of the fact that conclusions drawn from an elasticity-based analysis do not necessarily rest upon causal links. A ceteris paribus perspective (i.e., that all things are held constant except the two variables under analysis) is virtually unachievable in reality. It cannot be assumed that factual or political influences have the same effect on tax law systems across the jurisdictions under comparison.

To some extent, however, a historical perspective offers the opportunity of a ceteris paribus comparison. Provisions that only differ in respect of their period of application, but operate within the same jurisdiction might be compared, under the presumption that the relevant legal and factual circumstances remain constant. The smaller the span of time between the effective dates of the legal provisions, the more probable it becomes that circumstances remain the same. This provides at least some evidential basis for the causality between a change of the dependent variable and a change of the parameter. ${ }^{40}$ In the long run, however, even a historical perspective only shows correlations. Whether these interrelations are based on a causal link cannot be proved with absolute certainty.

\footnotetext{
${ }^{38}$ This method of comparative law applies a univariate approach, see above $\$ 4$ and $\mathrm{n} 21$; see in general U Mattei et al, 'Comparative Law and Economics', <http://encyclo.findlaw.com/0560book.pdf> [accessed 31 October 2012], at 505ff; E Towfigh \& N Petersen, Ökonomische Methoden im Recht (2010).

${ }^{39}$ The elasticity analysis is applied to legal transplants by Martini, above n 18, $24 \mathrm{ff}$.

${ }^{40}$ For the methodological similarities and differences of comparative law and legal history, cf K Richter, 'Perspektiven einer gemeinsamen Methodik in Rechtsvergleichung und Rechtsgeschichte', <http://www.klaus-richter.eu/veroeffentlichungen/sonstige-publikationen.html> [accessed 30 October 2012], 5ff; see also Reimer, above n 16, $105 \mathrm{ff}$.
} 
So, in all cases, the conclusions from the analysis of the reactions of the dependent variable to changes of the parameter remain merely indications. Still, as more comparisons are made, a causal link is more likely.

\subsubsection{Selecting the dependent variable}

The object of the comparison is the dependent variable, i.e. the legal area about which the comparative analysis wants to draw conclusions. Its scope is not determined by a comprehensive set of methods. The dependent variable can therefore be defined without constrictions. It is, however, necessary that it is based on a superordinate concept which connects different sub-concepts. Otherwise, the results of the interrelation of the variable and the parameter are not valid. It would not be possible to understand the differences between jurisdictions as a reaction to a change of the parameter.

If we focus on the legislator as addressee of comparative knowledge, two methods of choosing the dependent variable can be used. ${ }^{41}$ On the one hand, there is the general functional approach. Its starting point is not a legal question, but a factual problem. The objects to be compared are the functionally equivalent legislative reactions to the chosen factual problem. ${ }^{42}$ On the other hand, there is the understanding of comparative law as an observation and description of legal transplants. This method seems to significantly deviate from the functional approach. As explained below, however, it is just a special method to identify legislative reactions to factual problems. ${ }^{43}$

\footnotetext{
${ }^{41}$ See also $\$ 5.3 .4$, below.

${ }^{42}$ See in general Zweigert \& Kötz, above n 16, 33; specific aspects of comparative tax law are addressed by Garbarino (2009), above n 16, 686; Garbarino (2004, above n 16, 1070.

${ }^{43}$ Concerning the legal transplant in tax law see J-C Martinez, Le Statut de Contribuable (1980) 300ff; J-C Martinez \& P di Malta, Droit Fiscal Contemporain (1989) 414ff; Barker, above n 22, 114ff; Garbarino, above n 16, 677ff; C Garbarino, 'Comparative Taxation and Legal Theory: The Tax Design Case of the Transplant of General Anti-Avoidance Rules' (2010) 11 Theoretical Inquiries in Law 766; C Garbarino, 'Tax Transplants and Circulation of Corporate Models' (2011) British Tax Review 159; Martini, above n 18, 18; cf E Reimer, 'Transnationales Steuerrecht', in C. Möllers et al (eds), Internationales Verwaltungsrecht (2007) 197ff; see for the legal transplant in general A Watson, 'Legal Transplants and Law Reform' (1976) 92 Law Quarterly Review 79; A Watson, Legal Transplants (1993); G Deipenbrock, 'Legal Transplants? Rechtsvergleichende Grundüberlegungen zum technischen Rechtsnormtransfer' (2004) Zeitschrift für Vergleichende Rechtswissenschaft 343; G Rehm, 'Rechtstransplantate als Instrument der Rechtsreform und -transformation' (2008) 72 Rabels Zeitschrift für ausländisches und internationales Privatrecht 1; H Xanthaki, 'Legal Transplants in Legal Legislation: Defusing the Trap' (2008) 57 International and Comparative Law Quarterly 659. The idea of an understanding of comparative law as an analysis of
} 
These two methods of identifying the object of the comparison differ in respect of their scope. While the understanding of comparative law as an analysis of legal transplants only includes provisions that can be identified as receptions of foreign law, the functional approach embraces legal concepts that deal with the same factual problem, but do not originate from an import of foreign law. This difference can be illustrated by the different legislative reactions to tax avoidance techniques, such as the establishment of corporations in low tax jurisdictions. ${ }^{44}$ Legislative answers to this problematic either consist of specialised regimes, so-called controlled foreign company rules, which are based on concepts initially developed in the US ${ }^{45}$, or the application of pre-existing general anti-avoidance rules. ${ }^{46}$ While a comparison based on the functional method would include both types of rules, the approach focusing on legal transplants would only compare provisions dealing with controlled foreign companies in particular. Only these legislative instruments can be qualified as following from a transfer of concepts.

Nevertheless, the two approaches do not exclude each other. ${ }^{47}$ Legal transplants have to be understood as specific reactions of national legislators to a particular factual problem. In both approaches, the object of comparison is the legal reaction to a factual problem. The analysis of legal transfers merely contains an additional restriction. Hence, understanding comparative law as research on legal transfers can be conceived as a special method of identifying the objects of the comparison that is a subset of the functional approach and does not conflict with this approach. ${ }^{48}$

legal transfers is criticised by O Kahn-Freund, 'On Uses and Misuses of Comparative Law', (974) 37 The Modern Law Review 1; P Legrand, 'Impossibility of “Legal Transplants”' (1997) Maastricht Journal of European and Comparative Law 111; P Legrand, 'What "Legal Transplants?”, in D Nelken et al (eds), Adapting Legal Cultures (2001) $55 \mathrm{ff}$.

${ }^{44}$ In principle, income derived by such companies is only taxed at the low rate of their residence state. As long as the income is not distributed as a dividend, the shareholder's residence state is not entitled to tax. However, since the company is controlled by one or only a few shareholders, the time of the distribution is at their discretion.

${ }^{45}$ See sections 951ff, IRC. For example, this concept was altered by New Zealand (sections CQ 1ff, Income Tax Act) and Germany (\$\$ 7-14 International Tax Relations Tax Act). See in general B Arnold, The taxation of controlled foreign corporations: an international comparison (1986)

${ }^{46}$ See for example Austria: K Haslinger, 'National Report Austria', in M Lang et al (eds), CFC Legislation, Tax Treaties and EC Law (2004) $73 \mathrm{ff}$.

${ }^{47}$ A strict alternative, however, is favored by G Mousourakis, 'Transplanting Legal Models across Culturally Diverse Societies: A Comparative Law Perspective’ (2010) 57 Osaka University Law Review 87, $100 \mathrm{ff}$.

${ }^{48}$ Martini, above n 18, $22 \mathrm{ff}$. 


\subsubsection{Selecting the given parameter}

Besides the legal level, it is also possible to use factual criteria as a given parameter. The specialties of tax law, however, suggest the use of private law concepts. The unique connection of these two areas of law particularly requires a perspective that is not limited to one dimension. ${ }^{49}$ This purpose is fulfilled by the multivariate numerical based comparison. By comparing both national tax provisions and its private law environment, this method is able to draw conclusions about the grade of connection between these two areas of law.

For this purpose, the elasticity analysis does not require the synchronisation of legal terms in tax law and private law. Such synchronisation is virtually impossible in tax systems that apply in more than one private law jurisdiction. ${ }^{50}$ Even within a single jurisdiction, the fields of tax law and private law may differ in their understanding of particular legal terms and concepts. ${ }^{51}$ In the end, however, all tax systems use the legal structure of reality that private law provides: they all rely on notions such as ownership, property, and the idea of the corporation. However, all the different legal systems do so to a different extent. It is exactly these nuances that make the relationship between tax law and private law so suitable for an elasticity analysis: a change in private law will affect tax law differently in different legal systems. If the legal effects of a change in private law were invariably transferred to tax law without alterations, there would always be a proportional relationship between the dependent variable and the given parameter. The elasticity as a dynamic analysis would be deprived of one of its prerequisites. There would be no gradation of the reactions of one variable to the other. At the same time, the connection between tax law and private law is sufficiently close to warrant an elasticity analysis. This makes it possible to understand a change of the dependent variable (a tax law provision) as indicated by changes observed in the parameter (the private law environment). These indications make a causal link probable.

In order to guarantee a sufficient-and at the same time not too closeconnection between the two variables, the selection of the given parameter requires a pre-comparison on a macro level. This comparison is necessary to de-

\footnotetext{
${ }^{49}$ For discussion of multivariate analyses, see $\$ 5.1$, above.

${ }^{50}$ See e.g., Burnet v Harmel, 287 U.S. 103, 110 (Sup Ct 1932); for the UK, see J Tiley, 'United Kingdom', in H Ault \& B Arnold (eds), Comparative Income Taxation (2010) 166ff; for Canada, see B Arnold, 'Canada', in H Ault and B Arnold (eds), Comparative Income Taxation (2010) $39 \mathrm{ff}$.

${ }^{51}$ According to the German Constitutional Court of 27 December 1992 - 2 BvR 72/90, 1992 Bundessteuerblatt II 212, 213 there is no general assumption that terms of a tax act that also occur in private law have the same meaning in both legal areas.
} 
termine which private law concepts significantly interrelate with the dependent variable, i.e. the tax law concept. In general, both variables may neither be isolated nor characterised by a strict nexus. The elasticity analysis, however, does not require an interrelation between the two variables in every jurisdiction included in the comparison. A partial missing of an interaction makes the comparison especially valid in respect to tax systems in which the same tax concept shows an interrelation with private law. Hence, the macro comparison fulfils the purpose of providing for an adequate variety of dependent variables, parameters and interrelations among these concepts.

\subsubsection{The different grades of elasticity}

The next step in developing a comparative method out of the mathematical concept is to transfer the observed reactions of a tax law concept to the changes of the underlying (private law) concept. They must be translated into the different mathematical grades of responsiveness. In doing so, the most challenging issue is the difference in methodological 'languages'. While the mathematical concept of elasticity is based on a purely quantitative method, comparative law is-up to now-exclusively governed by qualitative linguistic methods. While mathematics always gives exact results, findings based on language data are, especially in their peripheral parts, interpretable and often not completely sustainable. ${ }^{52}$

The ambiguity of purely linguistic data of text-based comparisons does not allow an exact numerical translation. To some extent, this problem can be solved by a binary perspective. Such a perspective is solely focused on extremes and does not deliver a gradual translation. Thus, unlike mathematical elasticity, comparative elasticity is not based on ratio scales, but on interval scales. This difference, however, does not make the use of elasticity inappropriate a priori. For elasticity to be useful in comparative law, the mathematical model does not have to be translated exactly. In comparative law, elasticity fulfils a mere systemising and documenting function, aimed at achieving consistent results. Thus, it is used to translate language into numbers, which then become the basis of a legal comparison. For elasticity to fulfil this function, it does not need to operate on a ratio scale, but can use a nominal scale.

Thus, a numerical comparison is based on only two statuses. There can either be 'difference'

${ }^{52}$ Regarding the parallel problematic in law and economics, cf Petersen \& Towfigh, above n 38, $20 \mathrm{ff}$. 


$$
\left|\frac{\Delta y}{y}\right|>0 \wedge\left|\frac{\Delta x}{x}\right|>0
$$

or 'unaltered'

$$
\left|\frac{\Delta y}{y}\right|=0 \wedge\left|\frac{\Delta x}{x}\right|=0 .
$$

Regarding the first situation ('difference'), the changes of the dependent variable and the given parameter can be specified by:

$$
\Delta y=y_{i, j}-y_{k, l} \wedge \Delta x=x_{i, j}-x_{k, l}
$$

The indices $i, j, k$ and $l$ allow for the territorial and temporal allocation of the concept under comparison. $i$ and $k$ define the respective jurisdiction while $j$ and $l$ denominate the date when the concept is examined. The latter two indices make it possible to include a intertemporal perspective which allows for comparisons over time. Such intertemporal comparisons combine comparative law and legal history.

The possible values of the elasticity result from the following function

$$
\epsilon_{x_{i, j} x_{k, l} y_{i, j} y_{k, l}}=\frac{\frac{y_{i, j}-y_{k, l}}{y_{k, l}}}{\frac{x_{i, j}-x_{k, l}}{x_{k, l}}}
$$

There is, however, a need for a point of reference. Without such a point, the numerical value of the change of the dependent variable cannot be precisely determined. This does not mean, however, that the numerical translation is confined to $\frac{y_{i, j}-y_{k, l}}{y_{k, l}} \neq 0$. In fact, it is possible to modify the binary approach by enriching it with tendencies, i.e. ' + ' and '-', derived from the qualitative results. Such tendencies can be figured out by taking a particular national tax mechanism as the starting point of the analysis. The comparison will now give insights about the modifications seen from the perspective of that mechanism.

Thus, the decisive criterion that determines the algebraic sign of the variable is the affiliation to the initial tax mechanism represented by $y_{k, l}$. This makes it possible to distinguish between endogenous and exogenous modifications of the dependent variable. The demarcation between both types of modifications is characterised by the affiliation to another mechanism also being part of the same superordinate concept. While endogenous modifications are developed out of the specific mechanism itself, exogenous modifications are transferred from another 
mechanism. It has to be borne in mind, however, that determining the respective affiliation is still based on a mere qualitative comparison.

Modifications that are solely related to the initial point of reference sustain this mechanism as such and are not related to another mechanism. Such endogenous adaptations mean a 'plus' for the initial mechanism since it is developed internally. This is expressed by the term $y_{i, j}>y_{k, l}$. The relative change is defined by

$$
\frac{y_{i, j}-y_{k, l}}{y_{k, l}}>0
$$

On the contrary, exogenous effects can be observed if the modifications are related to another mechanism. Being an aliud from the perspective of the initial mechanism, these partial or total replacements result in a 'minus'. There is no development of the mechanism as such, but an insertion of external elements. Seen from the point of reference $y_{k, l}$, the variable $y_{i, j}$ is determined by the grade of the replacement. In the case of a partial replacement, the variables are determined by $y_{i, j}<y_{k, l} \wedge y_{i, j} \neq 0$. The elasticity is

$$
-1<\frac{y_{i, j}-y_{k, l}}{y_{k, l}}<0 .
$$

In the case of a total replacement, the perspective of the initial mechanism $\left(y_{k, l}\right)$ leads to $y_{i, j}=0$. This reflects the fact that this mechanism $\left(y_{i, j}\right)$ does not contain any elements of $y_{k, l}$. The relative change of the dependent variable is calculated as follows:

$$
\frac{y_{i, j}-y_{k, l}}{y_{k, l}}=-1
$$

In theory, the changes of the given parameter could also be differentiated into endogenous and exogenous modifications. The scope of the analysis, however, does not necessarily demand such a differentiation. It is mainly aimed at examining the dependent variable and its modifications and not at the legal environment as such, i.e. the parameter. This simplifies the comparative process. The findings are still controllable and can therefore constitute an appropriate basis for subsequent qualitative analysis. This means that the denominator of the elasticity function is characterised by a binary perspective. Either both jurisdictions differ or they are identical. Since there will virtually never be a perfect congruence, the grade of difference representing the demarcation between 'difference' and 'congruence' is determined by qualitative analysis. The 
researcher has to decide whether the situation in one jurisdiction significantly resembles the situation in the other jurisdiction or whether there is a significant difference.

In analogy to the total replacement of the dependent variable, a difference means $x_{i, j} \ll x_{k, l}$ and $x_{i, j} \rightarrow 0$. In the case of a congruence, the given parameters are characterised by $x_{i, j} \rightarrow x_{k, l}$. Thus, the denominator of the elasticity function can have two different values:

$$
\frac{x_{i, j}-x_{k, l}}{x_{k, l}} \rightarrow-1 \text { (difference) } \vee \frac{x_{i, j}-x_{k, l}}{x_{k, l}} \rightarrow 0 \text { (congruence) }
$$

Although infinitely small, the values of the latter equation are negative. A total congruence is virtually impossible, which leads to $x_{k, l}>x_{i, j}$.

Inserting the two different possibilities into the elasticity function results in:

$$
\varepsilon_{y_{i, j}, y_{k, l}, z}=\frac{\frac{y_{i, j}-y_{k, l}}{y+k, l}}{z} \text { cum } z \rightarrow-1 \vee \rightarrow 0 .
$$

The different elasticities of the dependent variable result from the combination of the three different types of relative changes on the one hand, and the two values of the denominator, i.e. the relative changes of the given parameter, on the other.

In the case of a coincidence of an endogenous modification and of a difference of the parameters, the elasticity calculates as

$$
\varepsilon_{y_{i, j}, y_{k, l}, z}<0 \text {. }
$$

If a partial replacement of the dependent variable meets a change of the given parameter, the elasticity is defined by

$$
\varepsilon_{y_{i, j}, y_{k, l}, z}>0 \text {. }
$$

In the case of a total replacement of the dependent variable, it is defined by

$$
\varepsilon_{y_{i, j}, y_{k, l}, z} \rightarrow 1 \text {. }
$$

The mathematical concept of elasticity does not address the question whether the dependent variable increases or decreases. It exclusively works with absolute values. Therefore, it cannot be transferred to the concept of exogenous and endogenous changes without adjustments. For the purposes of this transfer, the situation of a total replacement can be used as a point of reference. In this case, the 
mathematical concept can be applied without alterations. The dependent variable nearly reacts unitarily elastic. Changes of the given parameter are followed by a total replacement of the dependent variable. This relationship indicates that both variables under analysis, i.e. the national provisions, are connected to their respective parameters, i.e. the legal environment, in such a close manner that not even a partial replacement would allow for an adaption to another legal environment.

Transferring this interrelation to the concept of elasticity as whole means that, in the case of a difference of the given parameters, the results represent the extent to which the dependent variable reacts by replacements from other mechanisms: the more elastic the reaction, the closer the relationship between the given parameter and the tax mechanism. This thought determines the modifications of the mathematical concept. For purposes of comparative law, the demarcation is not determined by $\left|\varepsilon_{x, y}\right|<1$ and $\left|\varepsilon_{x, y}\right|>1$, but by negative and positive results. This means that a relatively elastic reaction is defined by $0<\varepsilon_{y_{i, j}, y_{k, l}, z}<1$. The provision under analysis reacts by replacements to changes of the legal environment. There is a loosened relationship of the two mechanisms under comparison to their respective parameters. In contrast to a unitarily elastic reaction, replacements of certain parts of the mechanism enable it to fulfil its function in an altered legal environment.

If $\varepsilon_{y_{i, j}, y_{k, l}, z}$ is negative $(<0)$, the variable reacts relatively inelastically. There is only a very limited reaction of the mechanism to a change of the environment. Such a relationship between the dependent variable and the given parameter indicates that the mechanism as such is able to function under both parameters without questioning its identity. The mechanism endogenously adapts to the changed environment and is not influenced by other mechanisms.

In the case of identical parameters in the jurisdictions under comparison, the denominator of the elasticity function approaches 0 . This means that the values of $\varepsilon_{y_{i, j}, y_{k, l}, z}$ are infinite or infinitesimal. This is supported by the fact that the elasticity does not change, no matter which type of exogenous change has taken place. A partial as well as a total replacement leads to $\varepsilon_{y_{i, j}, y_{k, l}, z} \rightarrow$ $\infty$. This means a perfectly elastic responsiveness of the variable to changes of the parameter. Although the changes of the parameter are infinitesimal, the variable changes. This indicates that the mechanism under analysis is very closely connected to its environment. It even reacts to very small changes. A transfer of such a mechanism to another environment does not seem to work without conflicts.

In the case of endogenous changes, the elasticity is defined by $\varepsilon_{y_{i, j}, y_{k, l}, z} \rightarrow$ 
$-\infty$ which means a perfectly inelastic reaction. The variable under analysis is virtually independent from the parameter. Despite the fact that the legal environment in both jurisdictions under comparison is identical, the mechanisms differ. Such modifications of the variable indicate that there is no or only a very limited connection to the given parameter. The changes are probably related to other influences that lie outside the scope of the analysis.

As already noted for the parameter, in the vast majority of cases the variable will not be perfectly identical. For the purpose of converting the mathematical elasticity into a legal method, this means that, to a certain extent, differences have to be ignored. It is sufficient that there is a qualified similarity. Systemic differences must be excluded. If the text-based comparison shows such qualified similarities, the variables are characterised by $y_{i, j} \rightarrow y_{k, l}$. The relative difference can be calculated using $\frac{y_{i, j}-y_{k, l}}{y_{k, l}} \rightarrow 0$. In addition, it has to be considered that $y_{k, l}$ is the point of reference for $y_{i, j}$ and that a complete congruence is virtually impossible. Thus, from the perspective of $y_{k, l}$, the variable $y_{i, j}$ is always slightly smaller. This means $y_{i, j}<y_{k, l}$. As a consequence, the numerator of the elasticity function is both infinitesimal and negative.

The given parameter is still characterised by the binary perspective:

$$
z \rightarrow-1 \text { (difference) or } z \rightarrow 0 \text { (congruence). }
$$

In the case of different parameters, the elasticity is defined by

$$
\varepsilon_{y_{i, j}, y_{k, l}, z} \rightarrow 0 \text { cum } \varepsilon_{y_{i, j}, y_{k, l}, z}>0 .
$$

In contrast to situations in which the variable changes, there is no need to adapt the mathematical values. The infinitesimal data minimises the effect of the negative or positive sign. Just like the mathematical model, $\varepsilon_{y_{i, j}, y_{k, l}, z} \rightarrow 0$ means a perfectly inelastic reaction. The comparison indicates that the mechanism used as dependent variable does not interact with the chosen concept represented by the two parameters. The mechanism seems to operate under both analysed frameworks without relevant malfunctions.

This result can also be transferred to a superordinate level. A perfectly inelastic reaction indicates that there is not only no interaction with the two parameters, but also with the underlying concept in total. The more jurisdictions and types of parameters are included in the comparison, the more valid the conclusion.

If the mechanism as well as the parameters do not differ at all, the elasticity analysis fails. The elasticity mathematically converges to 1 , but an essential 
precondition for the model is missing. There is no dynamic. Both $x$ and $y$ are virtually fixed. Even infinitesimal changes do not result in a measurable reaction. Accordingly, there is no leeway for any conclusion on a quantitative basis. At least there is a qualitative indication. The fact that two jurisdictions use virtually identical mechanisms suggests a connection between both areas. There is a certain probability that-in the case of a change of the parameter-the dependent variable would show an elastic reaction. Compared to the quantitative analysis, however, this indication which is solely based on congruence is rather weak. The mechanism and the parameter could also be combined by accident. A perfectly inelastic reaction of the variable is also possible. However, as more jurisdictions are included in the comparison, the conclusion of an elastic reactivity becomes more valid.

\subsubsection{Practical applicability and systematisation of the results}

This numerical methodology for comparative tax law is particularly helpful to national legislators. Comparative law mainly consists of the analysis of legislative mechanisms enacted in reaction to factual problems. Therefore, legal comparisons are always characterised by the element of lex ferenda. ${ }^{53}$ The elasticity analysis can be applied by national tax legislators in two ways. As the League of Nations pointed out, ${ }^{54}$ comparative analysis allows a precise as well as systematically consistent implementation of the concept under comparison into other jurisdictions. There is no danger of a rejection of the new mechanism by the legal environment. Already, in the course of the first implementation of a set of rules, the empirically-based indications make it possible to use those parts of a tax mechanism that do not conflict with the respective national system.

As far as provisions already in force are concerned, an elasticity analysis can also be very useful to identify necessary adaptions to the legal environment. This is particularly the case where one national system significantly deviates from the elasticities found in other jurisdictions. A combination of a tax mechanism that shows an elastic relation to a certain parameter with a different parameter indicates insufficient operating capability in practice. Using the results of the comparative analysis, the legislator is able to precisely reform parts of the

\footnotetext{
${ }^{53}$ Reimer, above n 16, 91; Infanti, above n 22, 1133; Garbarino, above n 16, 1081ff; Martinez \& di Malta, above $n$ 43, 301 describe national tax concepts as products of fiscal technology that are traded on an international market.

${ }^{54}$ See $\$ 2$, above.
} 
mechanism by using components that show an elastic relation to the national parameter.

Both purposes of the elasticity analysis are based on the following systematisation of dependent variable and given parameter:

\begin{tabular}{|c|c|c|c|c|}
\hline & $y_{i, j}=y_{k, l}$ & $\begin{array}{l}y_{i, j}>y_{k, l} \\
\text { endogenous } \\
\text { modification }\end{array}$ & $\begin{array}{l}y_{i, j}<y_{k, l} \\
\text { and } y_{i, j} \neq 0 \\
\text { partial } \\
\text { replacement }\end{array}$ & $\begin{array}{l}y_{i, j}=0 \\
\text { total } \\
\text { replacement }\end{array}$ \\
\hline$x_{i, j}=x_{k, l}$ & $\begin{array}{l}\text { qualitative } \\
\text { indication for } \\
\text { a elastic } \\
\text { relation }\end{array}$ & $\begin{array}{l}\varepsilon_{y_{i, j}, y_{k, l}, z} \rightarrow \\
-\infty \\
\text { perfectly } \\
\text { inelastic }\end{array}$ & $\begin{array}{l}\varepsilon_{y_{i, j}, y_{k, l}, z} \rightarrow \\
\infty \\
\text { perfectly } \\
\text { elastic }\end{array}$ & $\begin{array}{l}\varepsilon_{y_{i, j}, y_{k, l}, z} \rightarrow \\
\infty \\
\text { perfectly } \\
\text { elastic }\end{array}$ \\
\hline$x_{i, j} \neq x_{k, l}$ & $\begin{array}{l}\varepsilon_{y_{i, j}, y_{k, l}, z} \rightarrow \\
0 \\
\text { perfectly } \\
\text { inelastic }\end{array}$ & $\begin{array}{l}\varepsilon_{y_{i, j}, y_{k, l}, z}< \\
0 \\
\text { relatively } \\
\text { inelastic }\end{array}$ & $\begin{array}{l}0< \\
\varepsilon_{y_{i, j}, y_{k, l}, z}< \\
1 \\
\text { relatively } \\
\text { elastic }\end{array}$ & $\begin{array}{l}\varepsilon_{y_{i, j}, y_{k, l}, z} \rightarrow \\
1 \\
\text { unitarily } \\
\text { elastic }\end{array}$ \\
\hline
\end{tabular}

The relation between the dependent variable and the parameter represents the grade of the connection between them. The more elastic the relation, the more the variable's operating capability depends on the legal environment. The precondition of such an analysis is, however, that at least one of the two factors is subject to change. If both are identical, there is only a qualitative indication of a connection. Compared to the results of the mathematical model, this indication is rather weak.

Regarding all other cases, the closest connection between both factors can be found in the case of a perfectly elastic reaction. An infinitesimal change of the legal environment leads to a change of the mechanism which means that the concept which is the object of the analysis is very sensitive as far as the parameter is concerned. National legislators are warned that the mechanism in this shape will most probably not work under different parameters. At the same time, the provisions already implemented have to be carefully monitored in order to be able to swiftly react to probable rejections. In the case of such conflicts, there is the possibility to counteract these by partial replacements. Similar to the qualitative indication above, it should be borne in mind, however, that the results based on infinitesimal changes are only of limited significance. The difference between an infinitesimal change and a perfect congruence is virtually immeasurable. This 
means that, in this situation, the elasticity analysis is-to a certain extent-lacking its dynamic element.

A far more explicit indication of a connection between the dependent variable and the parameter can be found in the case of differing parameters. Especially perfectly unitarily reactions suggest a close connection. Such a reaction occurs if a difference in the parameter coincides with a total replacement of the variable. This indicates that the mechanism does not work in another legal environment. There is not even the possibility to adapt the mechanism by using partial replacements. As far as already existing provisions are concerned, a unitarily elastic relation indicates that exogenous changes related to another mechanism would result in conflicts with the legal environment.

Such problems do not arise in the case of a relative elasticity. In this situation, the mechanism principally works under different circumstances. It needs, however, stimulus from other concepts that have to be implemented by exogenous replacements. This is also the way to adapt already existing mechanisms to changes of the relevant parameters.

In the case of inelastic reactions, the mechanism only shows a marginal connection to the parameter or no connection at all. In this group, the relatively inelastic reaction is probably the most regular case. Such an interrelation means that the mechanism is able to work although there is an altered legal environment. In order to guarantee its functionality, however, there is a need for endogenous changes. The technical shape of these adaptations is specified by the elasticity analysis which precisely identifies the different solutions of the national legislators. Such a process enables legislative reforms to accurately integrate the mechanism in the national legal environment. At the same time, provisions already in force can be reformed by using the observed alterations while the legal parameters stay the same.

A similar reaction can be observed if the variable stays unaltered although the parameter changes. From the legislator's perspective, this situation differs from the aforementioned one. The comparison does not reveal any variations of the mechanism. The comparison only indicates that there is the possibility to introduce the mechanisms under analysis under different parameters. The jurisdictions included in the comparison do not suggest any potential for an endogenous development of the concept.

Exogenous and endogenous changes do not only differ in respect of the effect on the elasticity. They also have different positions as regards further analysis based on the results of the comparison. In contrast to exogenous replacements, adaptations offer the possibility to acquire positive comparative knowledge. The 
latter type of modifications does not only indicate inelastic interrelations; it also-positively-offers different potential shapes of the mechanism which can be used by legislators thinking about introducing or redesigning the concept.

With regard to exogenous changes, the comparative knowledge only consists of the identification of a conflict. The mechanism used as a point of reference will not work (properly) under changed parameters. Possibilities for an internal development of the concept are not offered. The national solutions for conflicts only consist in introducing a (partial) aliud. As this aliud is concerned, it merely indicates that it is incompatible with certain legal parameters. There is no positive knowledge for both mechanisms, but only the negative result that certain parts are not functional in a certain environment. Indeed, it has to be noted that exogenous replacements, just as endogenous changes, provide the basis for introducing the concept into a new environment without conflicts. Such a legislative process, however, results in a loss of the identity of the mechanism whose introduction was originally intended by the legislator. There is no positive insight about the further development of the mechanism as such. ${ }^{55}$

\subsubsection{Example: corporate income tax subjects and international company law}

A possible area of application of the elasticity method is the relationship between corporate income tax and international company law. In particular, the determination of corporate income tax subjects relies heavily on private law prerequisites. In particular, the international aspects of company law seem to have a tremendous influence on the shape of the personal corporate tax liability. ${ }^{56}$ This is why an analysis of the relationship between the mechanisms that determine corporate income tax subjects and the two main concepts of international company law (the 'real seat' theory and 'incorporation' theory) seems to be fruitful.

In brief, the dependent variable, i.e. the mechanisms identifying corporate tax subjects, can be divided into three groups. Based on private law, taxable

\footnotetext{
55 The positive and negative components of comparative knowledge are also addressed by Martini, above $\mathrm{n} 18,23$ and $25 \mathrm{ff}$.

${ }^{56}$ See for example the adaption of $\$ 1$ of the German Corporate Income Tax Act in 2006 as reaction on Case C-212/97, Centros, [1999] ECR, at I-1459; Case C-208/00, Überseering, [2002] ECR, at I-09919; Case C-167/01, Inspire Art, [2003] ECR, at I-10155.
} 
companies can either be named (formal designation) ${ }^{57}$ or identified by applying substantive private law criteria, e.g. liability or transferability of shares. ${ }^{58}$ In contrast, the third mechanism applies purely factual criteria to identify tax liability and does not rely on private law at all. An example would be the number of shareholders. ${ }^{59}$ Applying the elasticity method on the interrelation of these three mechanisms within the international company law environment (represented by $x$ ) leads to the following-highly condensed and simplified-results: ${ }^{60}$

\begin{tabular}{l|l|l|l} 
& $\begin{array}{l}\text { formal } \\
\text { designation }\end{array}$ & $\begin{array}{l}\text { substantive } \\
\text { private law } \\
\text { criteria }\end{array}$ & $\begin{array}{l}\text { factual } \\
\text { criteria }\end{array}$ \\
\hline $\begin{array}{l}x_{i, j}=x_{k, l} \\
\begin{array}{l}\text { identical } \\
\text { international } \\
\text { private law }\end{array}\end{array}$ & $\begin{array}{l}\varepsilon \rightarrow \infty \\
\text { perfectly elastic }\end{array}$ & $\begin{array}{l}\varepsilon \rightarrow \infty \\
\text { perfectly elastic }\end{array}$ & $\begin{array}{l}\varepsilon \rightarrow \infty \\
\text { perfectly } \\
\text { elastic }\end{array}$ \\
\hline $\begin{array}{l}x_{i, j} \neq y_{k, l} \\
\text { change from real } \\
\text { seat theory to } \\
\text { incorporation } \\
\text { theory or vice } \\
\text { versa }\end{array}$ & unitarily elastic & $\begin{array}{l}\varepsilon=0 \\
\text { intra-German } \\
\text { comparison: } \\
\text { perfectly inelastic } \\
0<\varepsilon<1\end{array}$ & $\begin{array}{l}\varepsilon \rightarrow 1 \\
\text { unitarily } \\
\text { elastic }\end{array}$ \\
& & $\begin{array}{l}\text { Germany-US: } \\
\text { relatively elastic }\end{array}$ &
\end{tabular}

In case of identical circumstances in international private law, all results show a perfectly elastic reaction of the mechanism. The comparison resulted in partial or total replacements. This indicates that all mechanisms are very

${ }^{57}$ See sec. 1(1) of the German Corporate Income Tax Act which lists, inter alia, the public business corporation $(\mathrm{AG})$ and the small business corporation $(\mathrm{GmbH})$.

${ }^{58}$ See for example the Dutch open limited partnership which is subject to corporate income tax due to the free transferability of the partnership share, Art. 2(1)(a) of the Dutch Corporate Income Tax Act.

${ }^{59}$ See for example the so-called Subchapter S corporations, sec. 1361(b)(1)(A) of the US Internal Revenue Code.

${ }^{60}$ Based on a comparison of Germany (Acts of 1891, 1920, 1925, 1934, and the current version of 2006), the Netherlands (Acts of 1819, 1893, 1924, 1916, 1917, 1940, 1942, and the current version of 1969), and the US (Acts of 1864, 1894, 1909, 1913, 1918, the entity classification until 1996, and the current entity classification); for details see R Martini, Der persönliche Körperschaftsteuertatbestand - Eine rechtsvergleichend-historische Analyse der Bestimmung von eigenständig steuerpflichtigen Personenvereinigungen (forthcoming 2014). 
closely connected to either the real seat theory or the incorporation theory. Combined with the results of the text-based comparison, the mechanisms can now be assigned to the respective private law concept which disassociates them from their national roots. Based on this comparative knowledge, tax legislators are now able to precisely decide about the mechanism that does not conflict with the part of the private law environment under analysis.

This result is largely confirmed in the situation of different international company law concepts. Both the formal designation and the use of factual criteria show a unitarily elastic reaction to the international company law theories. Changes of the given parameter are followed by a total replacement of the mechanism by another mechanism. Neither an endogenous development of the mechanism nor a partial replacement by other mechanisms would allow for an adaption to another international company law environment. Only the personal corporate tax liability based on substantive private law criteria shows a different reaction. The mechanism does not react at all to replacements (perfectly inelastic) or it is partially replaced (relatively elastic). This means that this mechanism is able to work under both international private law theories with no or only minor modifications. ${ }^{61}$ The combination of this result with the text-based comparison indicates-again by providing comparative knowledge-how this method of determining corporate income tax subjects has to be adapted.

\section{Perspectives of a numerical methodology}

Because of the strong connection between tax law and private law, a numerical approach is exceptionally suitable for comparative tax analysis. However, this approach could also sharpen comparative law methodologies in general. Text-based comparative methods aim at the identification of similarities and differences between legal systems. These results are then analysed using methods from other scientific disciplines, such as political science, sociology or economics. This, in essence, is not legal science. A numerical analysis of the similarities and differences, however, offers the possibility to systematise the results of text-based comparisons. At the same time, it multivariately correlates the object of the analysis with other legal concepts. This twofold comparison-substantially applying legal methods-enables comparative law to

\footnotetext{
${ }^{61}$ This result does not necessarily conflict with the situation of an unaltered private law environment. Since the empirical evidence of three jurisdictions and 20 points in time is rather limited, the analysis may contain accidental results.
} 
acquire knowledge exclusively relying on a comparison. In this way, comparative law may help pave the way for legal reform. 